\title{
Service Road Construction Using Cement Stabilized MSW at the Karadiyana Open Dumpsite, Sri Lanka
}

\author{
U. P. Nawagamuwa and P. D. A. Muthukumarana
}

\begin{abstract}
Dumping of municipal solid waste (MSW) on low-land is a waste disposal method used by most of the municipal councils in Sri Lanka. Rapid economic development, population growth, inadequate infrastructure and land scarcity have made it necessary to introduce improvements to MSW dump sites in the country. Setting up of new dumping sites is now being discouraged due to public pressure and steps are underway to optimize the existing dump yards. In this regard, the heights of the fills will have to be increased after the locations have been completely filled up with MSW although owing to poor style of dumping and very low bearing capacity of the fill, most of these locations will not be able to accommodate any further filling up. The situation at the dump site at Karadiyana is also same. Thus, a decision has been taken to have cement stabilized service roads as access roads to this dump site. Several samples were collected along the proposed service road stretch and basic studies on them were undertaken using Proctor compaction and California bearing ratio (CBR) tests to classify and investigate their present capacities. The values obtained are far below the values stipulated by ICTAD. After the MSW samples were stabilized with different cement proportions, it was observed that compared to the CBR of unimproved MSW, the CBR of cement stabilized MSW is significantly higher and that it exceeds the minimum value specified by ICTAD.
\end{abstract}

Keywords: $\quad$ MSW, Cement stabilization, Sub-base, CBR

\section{Introduction}

Sri Lanka is now in a transformation stage with regard to solid waste management with its focus being shifted from open dumping to engineered landfills. However, open dumping is still being practiced despite the huge pressure coming from the public. Basnayake and Visvanathan [1] reported that more than $60 \%$ of the solid waste generated is organic in nature with the prevailing MSW treatment and disposal methods being open dumping, landfilling, composting, anaerobic digestion and incineration. While continuing with open dumping, the authorities are now facing a critical issue when transporting and dumping the MSW at the same dumpsite but in areas farther away.

Karadiyana (Figure 1) is a typical open waste dumping site spreading out over 25 acres (10.1 ha) and situated in the Colombo district. The waste collected by Boralasgamuwa, Kesbawa, Panadura, Moratuwa, Dehiwala, Mount Lavinia and Kotte municipal councils are dumped there. It receives an average of 400 MT of solid waste daily from these 7 municipal areas located in and around Colombo and has been in existence for over thirty years.

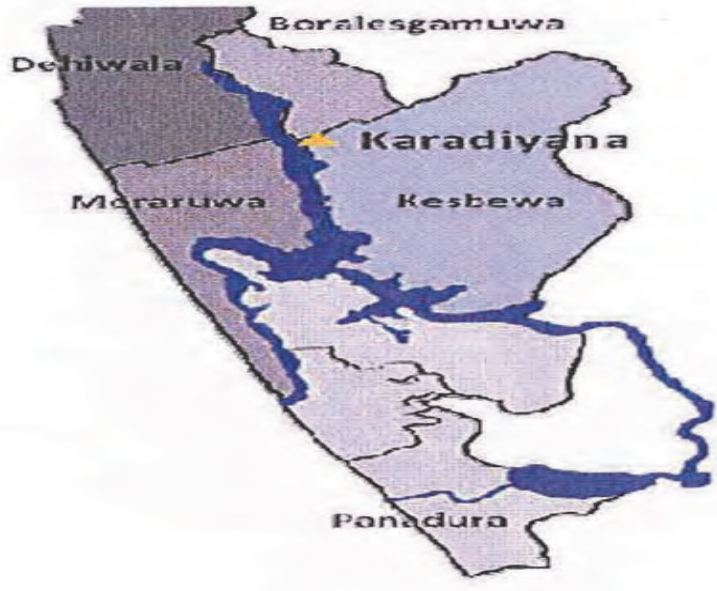

Figure 1 - Geographical location of Karadiyana dump site surrounded by seven municipalities.

Eng.(Dr.)U.P. Nawagamuwa,

B.Sc.Eng.Hons(Moratuwa), M.Eng(AIT), Dr.Eng(YNU),

C.Eng., FIE(SL), Senior Lecturer, Department of Civil

Engineering, University of Moratuwa.

Email:udeni@uom.lk

Eng. P.D.A. Muthukumarana, AMIE(SL)

Civil Engineer, National Water Supply and Drainage

Board, Sri Lanka.

Email:dharshaachalani@gmail.com 
Due to constraints faced in setting up new dumping locations, further dumping at the same location is being executed by constructing service roads to farther areas which have been abandoned due to overfills. However, it is learnt that the access to such locations on MSW would not be sustainable unless a reasonably operational service road network is constructed. Mixing MSW with soil and treating it with cement are some options available. This study was carried out to investigate the suitability of cement mixed MSW soils for use in such service roads.

\section{Use of MSW for Construction Activities}

Several studies have already been conducted on the required geotechnical properties of MSW and its inherent problems when MSW is to be used in the construction industry. Song et al., [2] have reported that MSW does not have much potential for its use as a sub base material in road construction due to its low shear strength and low bearing capacity. Geotechnical properties get affected considerably according to the quantity of organic matter contained in it. As the organic matter content increases, the maximum dry unit weight, shear strength and bearing capacity of the ground decrease, while void ratio and compressibility increase. However, Shariatmadari et al., [3] have reported that the organic content reduces as the age of MSW increases. Therefore, the effects of organic content of old MSW could be ignored.

During road construction on landfill areas, many problems such as embankment instability and ground settlement induced by traffic loads can occur. Therefore, the geotechnical engineering properties of a landfill site have to be investigated in detail (Sowers, [4]). However, soil improvement methods could be applied to solve stability problems or deformations in constructions that use MSW. Many techniques have been developed in the $20^{\text {th }}$ century by geotechnical engineers to improve the geotechnical characteristics and mechanical properties of soil. Using cement to improve those characteristics and properties is one of the traditional methods used in the road sector (Bell, [5], CRR, [6], and Estabragh et al., [7]). Cement could be considered as one of the oldest binding agents that has been in use since 1960s, the early stages of the introduction of the soil stabilization technology. It may be considered as either a primary stabilizing agent or a hydraulic binder since it can be used without any other material to bring about the stabilizing action required (Sherwood, [8] and EuroSoilStab, [9]). The reaction of cement is not dependent on soil minerals, and the key role expected of cement is to react with water that would be available in any type of soil (EuroSoilStab, [9]). Because of this reason, cement has been used to stabilize a wide range of soils. Numerous types of cements such as ordinary Portland cement, blast furnace cement, sulphate resistant cement and high alumina cement are available in the market. Usually, the type of cement chosen will depend on the type of soil to be treated with it and also the desired final strength of the soil. Portland cement has been used to stabilize soils used in pavement applications in thousands of miles of roadways all over the world (Makusa, [10]). Soil cement stabilization is best required for soils which are subject to changes in strength due to fluctuations of their moisture content. This applies to Karadiyana also in which the water table fluctuates due to marshy conditions underneath.

Hardening (setting) of cement will enclose soil as glue, but it will not change the structure of soil (EuroSoilStab, [9]). Cement hydration is a complex process with a complex series of unknown chemical reactions (Maclaren and White, [11]). Depending on the factor(s) involved, the ultimate effect on the setting and the strength of cement stabilized soil may vary. Although, the amount of cement used is normally small, it is sufficient enough to improve the engineering properties of the soil and the cation exchange of clay (Sherwood, [8]). Netterberg, [12] suggested that the curing period should be usually 7 days before having any traffic on the cement stabilized roads. AustStab [13] suggested that the likelihood of the movability of the fines due to erosion could be reduced in that type of stabilized layers. NCDOT [14] recommends making specimens using the optimum moisture content and a quantity of cement in the range of $5-12$ precent by weight.

Because of the positive features of the cement stabilized soils used in road sector applications, this study aims to utilize the same concept to improve the use of MSW in service roads of dumpsites. The study follows the specifications given by ICTAD [15] for the development of rural roads.

\section{Composition of the Waste Samples}

Three locations were identified as requiring improvements if they are to be used for service roads. MSW Samples A, B and C were collected 
from an area that has been earlier used for MSW dumping and which is now being used to access the new dumping areas. The geographical locations of the three sites from which the samples were collected are listed in Table 1. Samples obtained were from a depth of $0.3 \mathrm{~m}$ from the surface. According to site information, the selected MSW could be more than 5 years old. Random sampling was used in selecting the samples to ensure fair representation of the municipal solid waste. All samples were air dried sufficiently before they were tested. The composition of the municipal solid waste samples was ascertained by hand segregating and weighing the identical components of the waste samples according to the classification proposed by Hyun et al., [16]. Classification summary of the samples of the Karadiyana dump site indicating the percentage of items (on air dry weight basis) is presented in Table 2. Metals and soils are found to be dominant (on air dry weight basis) in all three locations. Figure 2 shows the individual components discovered in the MSW Sample A.

Table 1 - Details of the locations from which samples were collected

\begin{tabular}{|c|c|c|c|}
\hline \multirow{2}{*}{$\begin{array}{c}\text { Sample } \\
\text { identification }\end{array}$} & \multicolumn{2}{|c|}{ Co-ordinates } & \multirow{2}{*}{$\begin{array}{c}\text { Altitude } \\
\text { (Z) }\end{array}$} \\
\cline { 2 - 3 } & $\mathrm{N}$ & $\mathrm{E}$ & \\
\hline $\mathrm{A}$ & $6^{\circ} 48.675^{\prime}$ & $79^{\circ} 53.199^{\prime}$ & $21 \mathrm{~m}$ \\
\hline $\mathrm{B}$ & $6^{\circ} 49.756^{\prime}$ & $79^{\circ} 54.171^{\prime}$ & $23 \mathrm{~m}$ \\
\hline $\mathrm{C}$ & $6^{\circ} 48.880^{\prime}$ & $79^{\circ} 52.186^{\prime}$ & $24 \mathrm{~m}$ \\
\hline
\end{tabular}

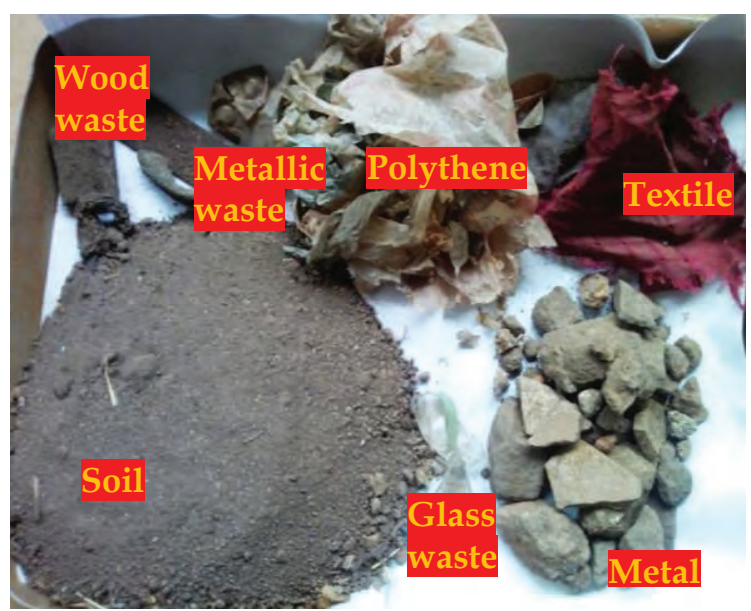

Figure 2 - MSW components discovered in Sample A

Table 2 - Percentage (on dry weight basis) of classified items found in Karadiayana

\begin{tabular}{|l|c|c|c|}
\hline $\begin{array}{l}\text { Classified } \\
\text { items (\%) }\end{array}$ & A & B & C \\
\hline Textiles & 0.33 & 0.21 & 0.14 \\
\hline Woods & 0.59 & 0.15 & 0.21 \\
\hline Metals & 23.38 & 14.66 & 10.37 \\
\hline Glass & 0.58 & 0.17 & 0.12 \\
\hline Polythene & 1.07 & 1.54 & 1.64 \\
\hline Metallic items & 2.84 & 2.24 & 0 \\
\hline Soil & 71.2 & 81.02 & 87.52 \\
\hline
\end{tabular}

Figure 3 - Grading curves of MSW Samples after wet sieving 


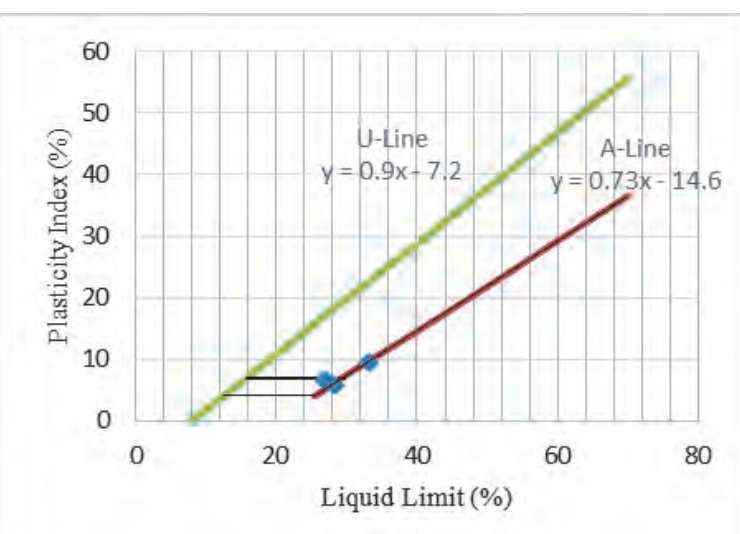

Figure 4 - Plasticity chart - Representation of Atterberg limits

\subsection{Classification of MSW}

Wet sieving (ASTM D 6913, [17]) was used on the air dried samples by washing them with water and passing them through a 75-micron sieve. The soil retained on the 75-micron sieve was collected and dried in an oven at $105^{\circ} \mathrm{C}$. The results obtained are presented in Figure 3. It has to be noted that polythene and textile particles were removed from the soil before it was wet sieved. The upper and lower boundary curves relate to the ICTAD [15] requirements for rural roads. As can be seen, the curves of all three samples fall within the ICTAD curves with Sample C only marginally satisfying the ICTAD stipulated conditions.

The Atterberg limits of the three soil samples were determined (ASTM D 4318, [18]) by passing them through a $425 \mu \mathrm{m}$ sieve. The results obtained are plotted on the plasticity chart (Figure 4) and the points could be considered as lying on the "A-line". Hence, using both Figures 3 and 4, Samples A, B and C could be classified as silty clayey sand (SM-SC) in accordance with the Unified Soil Classification System (USCS). ICTAD, [15] conditions for rural roads in respect of Atterberg limits require the liquid limit (LL) and the plasticity index (PI) to not to exceed $40 \%$ and $15 \%$ respectively. All 3 samples have satisfied well the said requirements.

The specific gravity of each sample was obtained by carrying out large pycnometer test (ASTM D 854, [19]) and the values obtained for samples A, B and C were 2.40, 2.45 and 2.50 respectively. These values are considerably lower than the specific gravity of traditional lateritic soils (2.65 - 2.70) used generally in road construction.

\subsection{Compaction Tests}

Standard Proctor Compaction Test (ASTM D 698,[20]) and 4 day soaked California Bearing
Ratio (CBR) Test (ASTM D 1883, [21]) were conducted on the three MSW samples. The results of the compaction test are presented in Figure 5 and it can be observed that the maximum dry density (MDD) of each of the samples is not sufficient to satisfy the ICTAD [15] requirement of $1750 \mathrm{~kg} / \mathrm{m}^{3}$. Based on a $100 \%$ maximum dry density, CBR tests were conducted on the samples. CBR values obtained for the A, B and C Samples were 8, 9 and 4 respectively. These values are far below the minimum CBR specified by ICTAD [15] which is 30\% for upper sub base material. As can be seen from Figure 3, Sample C does not comply with the ICTAD specified grading requirements. It can also be observed that Sample $C$ has the poorest performance with regard to both dry density and CBR. Hence, Sample $C$ would have to be improved with cement to observe an increase in its strength.

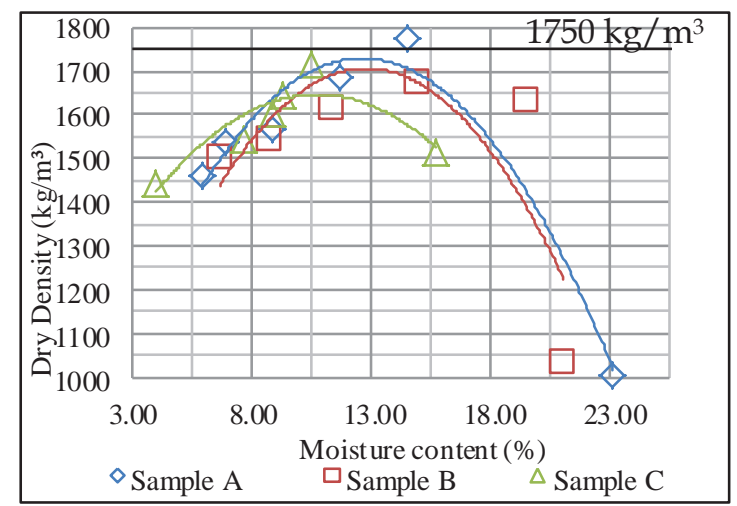

Figure 5 - Standard Proctor Compaction Tests results obtained before improving the soil

\section{Improvement of MSW with Cement}

The MSW of Sample C, the weakest of the three samples, was treated with cement to observe its behavior when it is used in sub base layers. In the laboratory testing program, Portland cement was used as a candidate stabilizer to treat/stabilize MSW soil. Therefore, the tests were carried out on Sample C after it was mixed with cement in the proportions of 3, 5 and 10 percent by the weight of air dried MSW. Standard Proctor compaction and 4 day soaked CBR tests were done on those samples and MDD, optimum moisture content and CBR were calculated. The results obtained are presented in Table 3 which shows a significant improvement in MDD and CBR values when compared to their values in unimproved material. This finding is graphically presented in Figure 6. However, for economic and practical reasons, a cement proportion of 5 
percent by weight of the MSW mixture could be recommended. High cement content could cause shrinkage cracks. However, it was observed that different quantities of materials such as polythene and textiles would reduce the tendency to form shrinkage cracks.

Table 3 - Properties of cement stabilized MSW

\begin{tabular}{|c|c|c|c|}
\hline $\begin{array}{c}\text { Cement } \\
\text { percentage } \\
(\%)\end{array}$ & $\begin{array}{c}\text { MDD } \\
\left(\mathrm{kg} / \mathrm{m}^{3}\right)\end{array}$ & $\begin{array}{c}\text { OMC } \\
(\%)\end{array}$ & $\begin{array}{c}\text { CBR } \\
(4 \text { day } \\
\text { soaked })\end{array}$ \\
\hline 0 & 1640 & 11 & 4 \\
\hline 3 & 1670 & 13 & 12 \\
\hline 5 & 1690 & 11 & 54 \\
\hline 10 & 1740 & 12 & 98 \\
\hline
\end{tabular}

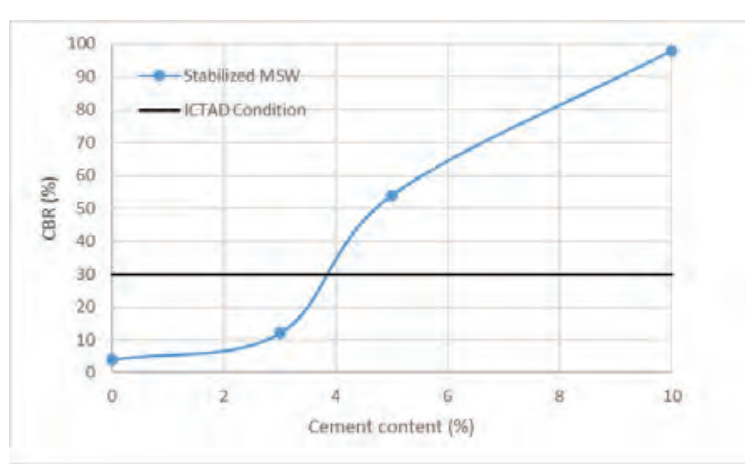

Figure 6 - CBR of MSW stabilized with cement

\section{Conclusions}

Laboratory tests were performed to investigate the geotechnical engineering properties of the MSW dumped at Karadiyana to ascertain its suitability for use as a sub base material in the site itself. Based on the results obtained, Sample C was identified to be the weakest sample because of its relatively poor geotechnical properties. Based on its performance after it has been treated with different cement percentages, the following conclusions could be made:

CBR value of the original MSW soil samples ranged from $4 \%$ to $9 \%$. CBR value of soil stabilized with cement increases when the cement content is increased from 0 to $10 \%$. It was revealed that a cement percentage of $5 \%$ would be sufficient to comply with the requirement specified by ICTAD [15] on CBR values. Observations made by other researchers also indicate that $5-10 \%$ of cement could be used to stabilize poor soils. It was observed that the shrinkage cracks caused by excess cement could be minimized by including in the soil non-granular materials such as polythene and textiles.

\section{Acknowledgement}

Authors wish to thank the staff at the Karadiyana dump site for the assistance extended to this research and also the staff of the Soil Mechanics Laboratory, University of Moratuwa for the invalubale assistance extended during the laboratory studies.

\section{References}

1. Basnayake, B. F. A., and Visvanathan, C., Solid Waste Management in Sri Lanka, Municipal Solid Waste Management in Asia and the Pacific Islands, Part of the series Environmental Science and Engineering, 2013, pp 299-316.

2. Song, Y. S., Yun, J. M., Hong, W. P. and Kim, T. H, Investigation of Solid Waste Soil as Road Construction Material", Article in Environmental Geology , 2003, · DOI: 10.1007 /s00254-002-07461.

3. Shariatmadari, N., Sadeghpour, A. H., and Mokhtari, M., Aging Effect on Physical Properties of Municipal Solid Waste at the Kahrizak Landfill, Iran. International Journal of Civil Engineering, Civil Engineering, 2015,pp. 126-136.

4. Sowers, G., Settlement of Waste Disposal Fills, Proceedings of the International Conference on Soil Mechanics and Foundation Engineering, International Society for Soil Mechanics and Foundation Engineering, Montreal, Quebec, Canada, 1973, 207-210.

5. Bell, F. G., "Lime Stabilization of Clay Minerals and Soils", Eng. Geol., 42(4), 1996, 223-237.

6. CRR 'Centre de recherches routières - Belgique', Code de Bonne Pratique Pour le Traitement des Sols à la Chaux et/ou Ciment Recommandations Pour le Recyclage des Terres", CRR, BelgiqueSomes, N. F., "Hoop Reinforced Concrete", Proc., ASCE, Vol. 96, ST7, 2004, pp. 1495-1509.

7. Estabragh, A. R., Pereshkafti, M. R. S., Prasaei, B. and Javadi, A. A., Stabilized Expansive Soil Behaviour during Wetting and Drying. International Journal of Pavement Engineering, 14(4), 2013, pp 418-427.

8. Sherwood, P., Soil Stabilization with Cement and Lime. State of the Art Review. London: Transport Research Laboratory, HMSO, 1993.

9. EuroSoilStab, Development of Design and Construction Methods to Stabilize Soft Organic Soils: Design Guide for Soft Soil Stabilization. CT97-0351, European Commission, Industrial and Materials Technologies Programme (RiteEuRam III) Bryssel, 2002. 
10. Makusa, G. P., Soil Stabilization Methods and Materials in Engineering Practice, PhD thesis, Luleå University of Technology, Sweden, 2012.

11. Maclaren, D. C. and White, M. A., Cement: Its Chemistry and Properties. Journal of Chemical Education, Vol.8 (No.6), 2013, pp 623-635.

12. Netterberg, F., Durability of Lime and Cement Stabilization, Technical note TS/9/87, NITRR, CSIR, Pretoria, 1987.

13. AustStab, Technical Note No. 5 Cement Stabilisation Practice, Pavement Recycling and Stabilization Association, Australia, 2012.

14. NCDOT, Chemical Stabilization Subgrade/ Base QA Field Manual, North Carolina Department of Transportation, Geotechnical engineering unit, Geopavement Section, Revised November 2015.

15. ICTAD, Standard Specifications for Construction \& Maintenance of Roads \& Bridges (ICTAD SCA/5) second edition, June 2009

ISSN: 1735-6865.

16. Hyun, I., P., Borinara, P. and Hong, K. D, Geotechnical Considerations for End-Use of Old Municipal Solid Waste Landfills, Int. J. Environ. Res., 5(3), 2011, pp 573-584.

17. ASTM D6913 - 04e1, Standard Test Methods for Particle-Size Distribution (Gradation) of Soils Using Sieve Analysis, 2009.

18. ASTM D4318 - 10e1, Standard Test Methods for Liquid Limit, Plastic Limit, and Plasticity Index of Soils, 2010.

19. ASTM D854 - 14, Standard Test Methods for Specific Gravity of Soil Solids by Water Pycnometer, 2014.

20. ASTM D698 - 12e2, Standard Test Methods for Laboratory Compaction Characteristics of Soil Using Standard Effort (12 $400 \mathrm{ft}-\mathrm{lbf} / \mathrm{ft}^{3}$ (600 kN$\left.\left.\mathrm{m} / \mathrm{m}^{3}\right)\right), 2014$.

21. ASTM D1883, Edition, March 1, 2016 Standard Test Method for California Bearing Ratio (CBR) of Laboratory-Compacted Soils, 2016. 